\title{
A New Phenanthrene Glycoside and Other Constituents from Dioscorea opposita
}

\author{
Marc Sautour,${ }^{a}$ Anne-Claire Mitaine-Offer,${ }^{a}$ Tomofumi Miyamoto, ${ }^{b}$ Hildebert Wagner, ${ }^{c}$ and \\ Marie-Aleth LaCAILle-Dubois ${ }^{*}, a$ \\ ${ }^{a}$ Laboratoire de Pharmacognosie, Unité UMIB, EA 3660, Faculté de Pharmacie, Université de Bourgogne; 7, Bd. Jeanne \\ d'Arc, BP 87900, 21079 Dijon Cedex, France: ${ }^{b}$ Graduate School of Pharmaceutical Sciences, Kyushu University; \\ Fukuoka 812-8582, Japan: and ${ }^{c}$ Center of Pharmaresearch, Pharmaceutical Biology, University of Munich; 81377 \\ Munich, Germany. Received February 23, 2004; accepted May 12, 2004
}

\begin{abstract}
Phytochemical investigation of the rhizome of Dioscorea opposita has led to the isolation of a new phenanthrene glycoside, 3,4,6-trihydroxyphenanthrene-3- $O$ - $\beta$-D-glucopyranoside (1), and five known compounds, soyacerebroside I (2), adenosine (3), $\beta$-sitosterol (4), palmitic acid (5) and palmitoyloleoylphosphatidylcholine (6). Their structures were determined by spectroscopic methods, including 1D- and 2D-NMR. Compounds 1-6 exhibited no antifungal activity against the human pathogenic yeasts Candida albicans, $C$. glabrata and $C$. tropicalis.
\end{abstract}

Key words Dioscorea opposita; Dioscoreaceae; phenanthrene glycoside; cerebroside, 2D-NMR

The Dioscorea genus includes an important group of tropical food yams, the edible portion of which is the tuber, or occasionally the bulbil. This is the case of the Chinese yam D. opposita ThunB (=D. batatas DeCNE) (Dioscoreaceae), which is widely cultivated in Asia as food. ${ }^{1,2)}$ This plant is also included in the Pharmacopoeia of the People's Republic of China and is widely used in traditional medicine for the treatment of anorexia, chronic diarrhoea, diabetes, seminal emission and excessive leukorrhea. ${ }^{3)}$ Previous phytochemical investigations carried out on D. opposita have resulted in the obtention of various constituents such as diosgenin, ${ }^{4)}$ gibberellins, ${ }^{5)}$ allantoin, ${ }^{6)}$ mucilages,${ }^{2)}$ phytoalexin, ${ }^{7)}$ dioscorin, ${ }^{8)}$ phenanthrene and bibenzyl derivatives (batatasins). ${ }^{9}$ ) As a part of our ongoing studies of the plants from the Dioscoreaceae family, ${ }^{10}$ a new phenanthrene glycoside, 3,4,6-trihydroxyphenanthrene-3- $O$ - $\beta$-D-glucopyranoside (1), was isolated together with five known compounds (2-6) from the rhizome of $D$. opposita. This paper describes the isolation and characterization by 2D-NMR of these compounds.

Six compounds were isolated from the Hexane and $\mathrm{MeOH}$ extracts of the rhizome of D. opposita, as described in Experimental. Compound 1, an amorphous solid, showed UV absorptions maxima at 222, 239 and $341 \mathrm{~nm}$. The IR spectrum exhibited absorptions at $3330(\mathrm{OH}), 2850(\mathrm{OMe}), 1737$ and $1435 \mathrm{~cm}^{-1}$ (aromatic rings). The high-resolution ESI mass spectrometry (HR-ESI-MS) (positive-ion mode) of $\mathbf{1}$ exhibited a pseudomolecular ion peak at $m / z 411.1075[\mathrm{M}+\mathrm{Na}]^{+}$ (Calcd 411.1056), consistent with a molecular formula of $\mathrm{C}_{20} \mathrm{H}_{20} \mathrm{O}_{8} \mathrm{Na}$. The ${ }^{1} \mathrm{H}-\mathrm{NMR}$ spectrum of 1 (Table 1) showed the presence of seven aromatic protons at $\delta 7.04,7.05,7.06$, 7.25 (d, $J=8.6 \mathrm{~Hz}), 7.42$ (d, $J=7.6 \mathrm{~Hz}), 7.59$ (s) and 7.94 (d, $J=7.4 \mathrm{~Hz}$ ), one anomeric proton at $\delta 5.29(\mathrm{~d}, J=7.9 \mathrm{~Hz})$, and six protons at $\delta$ in the $3.93-4.37 \mathrm{ppm}$ range due to the sugar residue. The ${ }^{13} \mathrm{C}-\mathrm{NMR}$ spectrum combined with the DEPT experiment of $\mathbf{1}$, showed the existence of 20 carbons, incluing one methylene carbon at $\delta 61.7$, four methine carbons at $\delta 70.7,74.3,77.5$ and 77.8 and one anomeric carbon at $\delta$ 102.3 from the sugar moiety, seven aromatic methine carbons at $\delta$ in the $111.8-124.8 \mathrm{ppm}$ range, and seven quaternary aromatic carbons at $\delta 109.5,118.8,127.8,137.0,144.0$,
151.1 and 153.3 , the last three being oxygenated. The presence of a sugar residue was determined to be a $\beta$-glucopyranosyl moiety by comparison of the ${ }^{13} \mathrm{C}$-NMR chemical shifts with literature values, ${ }^{10,11)}$ and its absolute configuration was determined to be D by GC analysis, as described in Experimental. The analysis of COSY, TOCSY, NOESY, HMQC and HMBC spectra was used to elucidate the structure and establish the ${ }^{1} \mathrm{H}$ - and ${ }^{13} \mathrm{C}$-NMR assignments of $\mathbf{1}$. Three pairs of ortho-coupled aromatic protons were observed through their ${ }^{1} \mathrm{H}-{ }^{1} \mathrm{H}$ COSY cross peaks between $\delta 7.05(\mathrm{H}-1)$ and $\delta 7.25$ (H-2), between $\delta 7.04(\mathrm{H}-7)$ and $\delta 7.94(\mathrm{H}-8)$ and between $\delta$ $7.06(\mathrm{H}-9)$ and $\delta 7.42(\mathrm{H}-10)$. In the HMBC spectrum (Fig.1), H-1 $(\delta 7.05)$ showed correlations with two aromatic carbons, C-3 $(\delta$ 151.1) and C-10 $(\delta 111.8)$, and H-2 $(\delta 7.25)$

Table 1. ${ }^{1} \mathrm{H}$ - and ${ }^{13} \mathrm{C}-\mathrm{NMR}$ Data of $\mathbf{1}$ (in Pyridine- $d_{5}$ ), ${ }^{a, b)} \delta$ in ppm, $J$ in $\mathrm{Hz}$

\begin{tabular}{|c|c|c|c|}
\hline \multirow{2}{*}{ No. } & \multicolumn{3}{|c|}{1} \\
\hline & $\delta_{\mathrm{C}}$ & $\delta_{\mathrm{H}}$ & HMBC correlations \\
\hline 1 & 116.2 & 7.05 & \\
\hline 2 & 118.5 & $7.25 \mathrm{~d}(J=8.6)$ & \\
\hline 3 & 151.1 & & $\mathrm{H}-1, \mathrm{H}-2, \mathrm{H}-1^{\prime}$ \\
\hline 4 & 153.3 & & $\mathrm{H}-2$ \\
\hline $4 a$ & 109.5 & & $\mathrm{H}-5$ \\
\hline $4 \mathrm{~b}$ & 137.0 & & $\mathrm{H}-5, \mathrm{H}-8, \mathrm{H}-9$ \\
\hline 5 & 124.8 & $7.59 \mathrm{~s}$ & \\
\hline 6 & 144.0 & & $\mathrm{H}-7$ \\
\hline 7 & 119.0 & 7.04 & \\
\hline 8 & 118.7 & $7.94 \mathrm{~d}(J=7.4)$ & \\
\hline $8 \mathrm{a}$ & 127.8 & & H-5, H-7, H-10 \\
\hline 9 & 121.5 & 7.06 & $\mathrm{H}-8$ \\
\hline 10 & 111.8 & $7.42 \mathrm{~d}(J=7.6)$ & $\mathrm{H}-1$ \\
\hline $10 \mathrm{a}$ & 118.8 & & $\mathrm{H}-9, \mathrm{H}-10$ \\
\hline $1^{\prime}$ & 102.3 & $5.29 \mathrm{~d}(J=7.9)$ & \\
\hline $2^{\prime}$ & 74.3 & 4.14 & \\
\hline $3^{\prime}$ & 77.5 & 4.26 & \\
\hline $4^{\prime}$ & 70.7 & 4.14 & \\
\hline $5^{\prime}$ & 77.8 & 3.93 & \\
\hline $6^{\prime}$ & 61.7 & $4.20,4.37$ & \\
\hline
\end{tabular}

a) The assignments were based on DEPT, HMQC, and HMBC experiments (150 MHz for ${ }^{13} \mathrm{C}-\mathrm{NMR}, 600 \mathrm{MHz}$ for ${ }^{1} \mathrm{H}-\mathrm{NMR}$ ). b) Overlapping ${ }^{1} \mathrm{H}-\mathrm{NMR}$ signals are reported without designated multiplicities. 


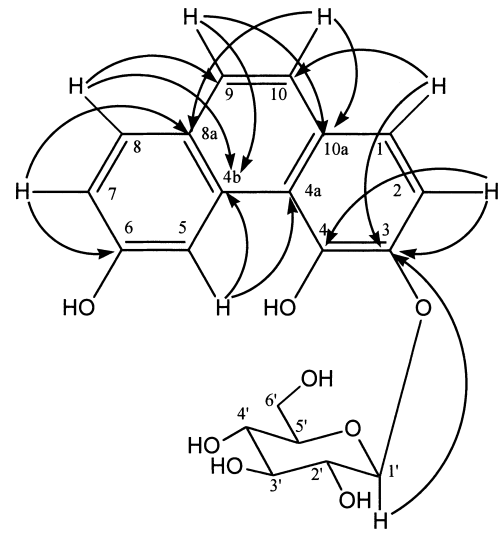

Fig. 1

correlated with $\mathrm{C}-3(\delta$ 151.1) and C-4 $(\delta$ 153.3), respectively. $\mathrm{H}-5$, an isolated proton $(\delta 7.59, \mathrm{~s})$, showed HMBC correlations with three quaternary carbons C-4a $(\delta$ 109.5), $\mathrm{C}-4 \mathrm{~b}(\delta 137.0)$ and $\mathrm{C}-8 \mathrm{a}(\delta 127.8)$. Cross peaks were equally observed between $\mathrm{H}-7(\delta$ 7.04) and C-6 $(\delta$ 144.0) and C-8a $(\delta$ 127.8). Additional HMBC correlations were observed between H-8 $(\delta$ 7.94) and C-4b $(\delta$ 137.0) and C-9 $(\delta$ 121.5), between H-9 $(\delta$ 7.06) and C-4b $(\delta$ 137.0 $)$ and C-10a $(\delta$ 118.8), and between H-10 $(\delta$ 7.42) and C-8a $(\delta$ 127.8) and $\mathrm{C}-10 \mathrm{a}(\delta$ 118.8). All these data suggested the presence of a 3,4,6-trisubstitued phenanthrene. ${ }^{12}$ ) The HMBC correlation between $\mathrm{H}-1^{\prime}(\delta 5.29, \mathrm{~d}, J=7.9 \mathrm{~Hz})$ of the glucopyranosyl residue and C-3 $(\delta 151.1)$, and the NOESY correlation between $\mathrm{H}-1^{\prime}(\delta 5.29)$ and $\mathrm{H}-2(\delta 7.25)$, indicated the attachment of a glucopyranosyl moiety at C-3 of the phenanthrene residue. Thus, the structure of 1 was established to be 3,4,6trihydroxyphenanthrene-3- $O-\beta$-D-glucopyranoside (Fig. 1), a new natural compound. ${ }^{13)}$

The only reports of the isolation of phenanthrene glycosides concerned plants from the Orchidaceae family ${ }^{12,14)}$; it is, to the best of our knowledge, the first report of the isolation of such secondary metabolites from the Dioscoreaceae family.

Compounds $\mathbf{2}-\mathbf{6}$ were identified by interpretation of their spectral data, mainly FAB-MS and 2D-NMR (COSY, NOESY, HMBC, HMQC), as well by comparison with literature data as soyacerebroside I (2), ${ }^{15)}$ adenosine $(3),{ }^{16)} \beta$-sitosterol (4), ${ }^{17)}$ palmitic acid (5), ${ }^{16)}$ and 1-O-palmitoyl-2-Ooleoyl-glycero-3-phosphocholine or 1-O-oleoyl-2- $O$-palmitoyl-glycero-3-phosphocholine (6), ${ }^{13)}$ respectively.

Soyacerebroside I (2) has been previously isolated from Glycine max (Leguminoseae), ${ }^{18)}$ Prunus jamasakura (Rosaceae), ${ }^{19)}$ and Dimocarpus fumatus and Longan arillus (Sapindaceae) ${ }^{15,20)}$ Plant cerebrosides are of interest because they have been shown to be cytotoxic, ${ }^{21)}$ anti-ulcerogenic, ${ }^{22}$ and hepatoprotective. ${ }^{23)}$ To our knowledge, the isolation of $\mathbf{2}$ from Dioscorea opposita is the first account of the isolation of a cerebroside from the Dioscoreaceae family. ${ }^{13)}$

Previous phytochemical investigations carried out on Dioscorea opposita have resulted in the obtention of antifungal compounds such as phytoalexins. ${ }^{7)}$ Nevertheless, compounds $\mathbf{1}-\mathbf{6}$ were devoid of antifungal activity against Candida albicans, C. glabrata and C. tropicalis with MICs $>200 \mu \mathrm{g} / \mathrm{ml}$.

\section{Experimental}

General IR spectra were recorded on a Perkin-Elmer 281 spectrophotometer. UV spectra were performed using a Uvikon 931 spectrophotometer. GC analysis was carried out on a Termoquest gas chromatograph using a DB-1701 capillary column $(30 \mathrm{~m} \times 0.25 \mathrm{~mm}$, i.d.) (J \& W Scientific), detection by FID, with the initial temperature maintained at $80^{\circ} \mathrm{C}$ for $5 \mathrm{~min}$ and then raised to $270^{\circ} \mathrm{C}$ at the rate of $15^{\circ} \mathrm{C} / \mathrm{min}$, carrier gas: He. Optical rotations were taken with a Perkin-Elmer 241 polarimeter. The HR-ESI-MS was measured in positive ion mode on a Q-TOF 1-micromass spectrometer. 1D- and 2D-NMR spectra $\left({ }^{1} \mathrm{H}-{ }^{1} \mathrm{H}\right.$ COSY, TOCSY, NOESY, HMQC and HMBC) were measured on a UNITY-600 spectrometer at the operating frequency of $600 \mathrm{MHz}$ on a Varian INOVA 600 instrument equipped with a SUN 4 L-X computer system $\left(600 \mathrm{MHz}\right.$, for ${ }^{1} \mathrm{H}$ and $150 \mathrm{MHz}$ for ${ }^{13} \mathrm{C}-\mathrm{NMR}$ spectra). All chemical shifts $(\delta)$ are given in ppm, and the compounds were solubilized in pyridine- $d_{5}$. Column Chromatography (CC) was carried out on a Sephadex LH-20 (Pharmacia), silica gel column $(63-200 \mu \mathrm{m})$. Vacuum Liquid Chromatography (VLC) was performed on $\mathrm{C}_{18}$ reversed-phase $(12 \times 3 \mathrm{~cm})$. Medium-Pressure Liquid Chromatography (MPLC) was carried out using a silica gel 60 (Merck, 15-40 $\mu \mathrm{m}$ ) with a Gilson pump M 305, and eluted with $\mathrm{CHCl}_{3}-\mathrm{MeOH}-\mathrm{H}_{2} \mathrm{O}$ (13:7:2, lower phase). TLC was performed on silica gel $60 \mathrm{~F}_{254}$ (Merck), detected by spraying with Komarowsky reagent, a $(5: 1)$ solution of $2 \%$ 4-hydroxybenzaldehyde in $\mathrm{MeOH}$ and $50 \% \mathrm{H}_{2} \mathrm{SO}_{4}$.

Plant Materials The rhizomes of D. opposita, harvested in April 1998 in Hexan province (China), were identified by Pr. Dr. H. Wagner. A voucher specimen was deposited under the number 3533 in the herbarium of the Laboratory of Pharmacognosy, University of Dijon, France.

Extraction and Separation Dried powdered rhizomes (400 g) were submitted to successive extractions in a Soxhlet by hexane $(31,24 \mathrm{~h})$, $\mathrm{CH}_{2} \mathrm{Cl}_{2}(3 \mathrm{l}, 24 \mathrm{~h})$ and $\mathrm{MeOH}(41,48 \mathrm{~h})$. After evaporation of the solvent, the corresponding hexane $(1.08 \mathrm{~g}), \mathrm{CH}_{2} \mathrm{Cl}_{2}(1.31 \mathrm{~g})$ and $\mathrm{MeOH}(24.2 \mathrm{~g})$ extracts were obtained. The $\mathrm{MeOH}$ extract was dissolved in $400 \mathrm{ml} \mathrm{H}_{2} \mathrm{O}$ and partitioned with $n$-BuOH $(3 \times 300 \mathrm{ml})$. One part of the $n-\mathrm{BuOH}$ extract $(2 \mathrm{~g})$ was subjected to VLC, then eluted with $\mathrm{H}_{2} \mathrm{O}$ containing increasing amounts of $\mathrm{MeOH}$. The fraction eluted with $\mathrm{MeOH}-\mathrm{H}_{2} \mathrm{O}(1: 4)$ was finally submitted to MPLC to yield $1(6 \mathrm{mg})$. Another part of the $n$-BuOH extract $(4 \mathrm{~g})$ was submitted to CC (Sephadex LH-20, MeOH) to give 7 fractions. Fraction 2 (1 g) was submitted to MPLC, as previously described, yielding $2(12 \mathrm{mg})$. Fraction $6(82 \mathrm{mg})$ was treated in the same way to give $\mathbf{3}(10 \mathrm{mg})$. The hexane extract was chromatographed on a silica gel column $(63-200 \mu \mathrm{m})$, and eluted with $\mathrm{CHCl}_{3}$ containing increasing amounts of $\mathrm{MeOH}$, to give 7 fractions. The fraction $\mathrm{CHCl}_{3}-\mathrm{MeOH}(98: 2)$ (125 mg) was rechromatographed in the same way to yield compounds $4(15 \mathrm{mg})$ and $\mathbf{5}(18 \mathrm{mg})$. The fraction $\mathrm{CHCl}_{3}-\mathrm{MeOH}(92: 8)(160 \mathrm{mg})$ was treated in the same way to yield 6 (13 $\mathrm{mg})$.

3,4,6-Trihydroxyphenanthrene-3-O- $\beta$-D-glucopyranoside (1): Amorphous solid, HR-ESI-MS (positive ion-mode) $\mathrm{m} / \mathrm{z}: 411.1075[\mathrm{M}+\mathrm{Na}]^{+},(\mathrm{Calcd}$ for $\left.\mathrm{C}_{20} \mathrm{H}_{20} \mathrm{O}_{8} \mathrm{Na}: 411.1056\right)$. $[\alpha]_{\mathrm{D}}^{20}-16^{\circ}(c=0.25, \mathrm{MeOH})$. IR $v_{\max }\left(\mathrm{CHCl}_{3}\right)$ $\mathrm{cm}^{-1}$ : 3330, 2850, 1737 and 1435. UV $\lambda_{\max }(\mathrm{MeOH}) \mathrm{nm}: 222,239,341 .{ }^{1} \mathrm{H}-$ and ${ }^{13} \mathrm{C}$-NMR: see Table 1 .

Acid Hydrolysis A solution of compound $1(3 \mathrm{mg})$ in $2 \mathrm{~N}$ aqueous $\mathrm{CF}_{3} \mathrm{COOH}(5 \mathrm{ml})$ was refluxed on a water bath for $3 \mathrm{~h}$. After extraction with $\mathrm{CH}_{2} \mathrm{Cl}_{2}(3 \times 5 \mathrm{ml})$, the aqueous layer was repeatedly evaporated to dryness with $\mathrm{MeOH}$ until neutral, then glucose was identified by TLC with a standard using $\mathrm{CHCl}_{3}-\mathrm{MeOH}-\mathrm{H}_{2} \mathrm{O}(8: 5: 1)$. Furthermore, a silylated derivate of the sugar was prepared according to the procedure previously described. ${ }^{11)}$ L-Cysteine methyl ester hydrochloride $(0.06 \mathrm{~mol} / \mathrm{l})$ and HMDSTMCS (hexamethyldisilazane-trimethylchlorosilane, $3: 1$ ) were added to the aqueous residue. After centrifugation of the precipitate, the supernatant was concentrated and partitioned between $n$-hexane and $\mathrm{H}_{2} \mathrm{O}$, and the hexane layer was analyzed by GC. D-Glucose was detected.

Antifungal Bioassay Minimum inhibitory concentrations (MICs) were performed using the broth dilution test. ${ }^{24)}$ For these bioassays, three human pathogenic yeasts were used: Candida albicans (IP 1180-79), C. glabrata and C. tropicalis (clinical isolates).

Acknowledgments The authors thank Dr. F. Libot, University of Paris $\mathrm{V}$, France, for the measurement of HR-ESI-MS.

\section{References}

1) Ireland C. R., Schwabe W. W., Coursey D. G., Phytochemistry, 20, 1569-1571 (1981)

2) Tomoda M., Ishikawa K., Yokoi M., Chem. Pharm. Bull., 29, 32563261 (1981). 
3) "Pharmacopoeia of the People's Republic of China," Eng. Ed., Vol. 1, Chemical Industry Press, Beijing, China, 1997.

4) Yang W. Y., Xiong C., Fenxi Shiyanshi, 21, 74-75 (2002).

5) Tanno N., Yokota T., Abe M., Okagami N., Plant Physiol., 100, 1823 -1826 (1992).

6) Ninomiya A., Murata Y., Tada M., Shimoishi Y., J. Jpn. Soc. Hortic. Sci., 72, 321-323 (2003).

7) Tagasugi M., Kawashima S., Monde K., Katsui N., Masamune T., Shirata A., Phytochemistry, 26, 371-375 (1987).

8) Hou W. C., Chen H. J., Chang C. F., Lin Y. H., Plant Science, 149, $151-156$ (1999).

9) Tang W., Eisenbrandt G., "Chinese Drugs of Plant Origin. Chemistry, Pharmacology and Use in Traditional and Modern Medicine," Springer-Verlag, Berlin, 1992.

10) Sautour M., Mitaine-Offer A. C., Miyamoto T., Dongmo A., LacailleDubois M. A., Planta Med., 70, 90-92 (2004).

11) Haddad M., Miyamoto T., Laurens V., Lacaille-Dubois M. A., J. Nat. Prod., 66, 372-377 (2003).

12) Yamaki M., Kato T., Bai L., Inoue K., Takagi S., Phytochemistry, 34, 535-537 (1993).

13) Buckingham J. B., "Dictionary of Natural Products on CD-ROM," Version 11: 2, Chapman and Hall, CRC Press, London, U.K. 2003.
14) Ye Q. H., Zhao, W. M., Qin G. W., Nat. Prod. Res., 17, 201-205 (2003).

15) Voutquenne L., Lavaud C., Massiot G., Sevenet T., Hadi H. A., Phytochemistry, 50, 63-69 (1999).

16) Pretsch E., Clerc T., Seibl J., Simon W., "Tables of Spectral Data for Structure Determination of Organic Compounds," Springer-Verlag, Berlin, 1989.

17) De-Eknambul W., Potduang B., Phytochemistry, 62, 389-398 (2003).

18) Shibuya H., Kawashima M., Sakagami M., Kawanishi H., Shimomura M., Ohashi K., Kitagawa I., Chem. Pharm. Bull., 38, 2933-2938 (1990).

19) Yoshioka A., Etoh H., Yagi A., Sakata K., Ina K., Agric. Biol. Chem., 54, 3355-3356 (1990).

20) Ryu J., Kim J. S., Kang S. S., Arch. Pharm. Res., 26, 138-142 (2003).

21) Wenzao J., Rinehart K. L., Jares-Erijman E. A., J. Org. Chem., 59, 144 (1994).

22) Okuyama E., Yamazaki M., Chem. Pharm. Bull., 31, 2209-2219 (1983).

23) Jang Y. P., Lee Y. J., Kim Y. C., Huh H., Plant Cell. Rep., 18, 252254 (1998).

24) Quiroga E. N., Sampietro A. R., Vattuone M. A., J. Ethnopharmacol., 74, 89-96 (2001). 